\title{
AS DIRETIVAS ANTECIPADAS DE VONTADE E O LIVRE CONSENTIMENTO
}

\section{THE ADVANCE DIRECTIONS OF THE WILL AND THE FREE CONSENT}

FABIANA CARICATI

Advogada. Mestranda do Programa de Pós-Graduação Strictu Sensu em Direito Empresarial e Cidadania no Centro Universitário Curitiba - Unicuritiba, Paraná. email: fabiana@caricati.adv.br.

\section{CLAYTON REIS}

Professor Orientador. Doutor em Direito pela Universidade Federal do Paraná. Mestre em Direito pela Universidade Federal do Paraná. Bacharel em Direito pela Faculdade de Direito de Curitiba. Magistrado em Segundo Grau, aposentado, do TJPR. Professor na Escola da Magistratura do Paraná e pertence ao Corpo Docente Permanente do Programa de Mestrado em Direito Empresarial e Cidadania do UNICURITIBA. email: claytonreis43@gmail.com.

\section{OBJETIVOS}

Atualmente, muito tem se falado sobre o testamento vital, instrumento usado para fazer prevalecer a vontade de pacientes em estado terminal ou vegetativo, quanto a quais procedimentos médicos querem ou não ser submetidos.

Apesar de vulgarmente conhecido como testamento vital, o instituto está regulado pela Resolução № 1995/2012 do Conselho Federal de Medicina que o designa como "Diretivas Antecipadas de Vontade", contudo, o tema é bastante 


\section{Personalidade Acadêmica Homenageada:}

\section{Carlos Aurélio Mota de Souza (Universidade Ibirapuera - UNIB)}

controvertido já que inexiste lei positivando este instituto no ordenamento jurídico brasileiro, inexistindo definição clara dos requisitos que deverão ser observados para sua elaboração, como também inexiste orientação sobre seu efeito obrigatório ou não em relação ao profissional da saúde que está atendendo aquele paciente.

A justificativa hoje aceita para o instituto é a necessidade de fazer prevalecer a vontade desses pacientes perante os tratamentos médico-hospitalares, assegurando a dignidade da pessoa humana, a autonomia privada e a proibição constitucional de tratamento desumano, já que um paciente em estado terminal já está sofrendo o bastante para se submeter a procedimentos médicos que causarão sofrimentos ainda maiores e desnecessários, visto que já se encontra no fim da vida e sem possibilidade de cura.

Diante desta problemática, o presente trabalho buscou analisar este instrumento partindo da doutrina civilista sobre o testamento e suas espécies. Em seguida, buscou-se apresentar os elementos fundantes das diretivas antecipadas de vontade, seus efeitos, fundamentos jurídicos e requisitos, dentre eles o consentimento livre e esclarecido, que de fato seria o ingrediente fundante para sua aplicação, irradiando seus efeitos vinculantes aos profissionais da saúde, em atendimento aos princípios constitucionais acima mencionados.

\section{METODOLOGIA}

Para as investigações de caráter dedutivo, serviram de fonte de pesquisa a análise bibliográfica, jurisprudencial e a coleta de dados em trabalhos elaborados em programas de pós-graduação strictu sensu, os quais retratam a doutrina difundida em relação ao instituto das diretivas antecipadas de vontade.

\section{RESULTADOS}

Não havendo definição legal do denominado testamento vital ou biológico, buscouse na doutrina sua conceituação. Segundo ensina Carlos Roberto Gonçalves (GONÇALVES, 2015), o instituto constitui uma declaração unilateral de vontade em 


\section{Personalidade Acadêmica Homenageada:}

Carlos Aurélio Mota de Souza (Universidade Ibirapuera - UNIB)

que a pessoa manifesta o desejo de ser submetida a determinado tratamento, na hipótese de se encontrar doente, em estado incurável ou terminal, ou apenas declara que não deseja ser submetida a nenhum procedimento que evite a sua morte.

Dessa forma, a pessoa escolhe, enquanto capaz, por escrito, o tratamento médico que deseja receber ou manifesta o desejo de não se submeter a nenhum deles. Esta declaração de vontade do paciente acaba por influenciar na conduta médica e limita a atuação da família, caso a doença progrida e venha a se tornar impossibilitado de manifestar a sua vontade.

De acordo com a resolução do Conselho Federal de Medicina, trata-se de um registro histórico-clínico que o paciente poderá fazer dispondo sobre sua vontade de se submeter ou não a tratamentos invasivos ou dolorosos para prolongar sua vida em situações terminais crônicas ou estados vegetativos.

Também, segundo as orientações do Conselho Federal de Medicina, o paciente poderá fazer uso do documento a qualquer momento, desde que maior de idade e em pleno gozo de suas faculdades mentais, cuja declaração passará a servir de suporte legal e ético para os médicos.

A falta de previsão legal do instituto no Brasil representa um retrocesso para o país, devendo sua análise e validade se dar através da Resolução no 1.995/12 do Conselho Federal de Medicina e da análise de princípios jurídicos constitucionais, assim, pelo fato de tema ainda não estar positivado, o instituto acaba sendo pouco conhecido e pouco utilizado, devido à grande insegurança jurídica existente para os pacientes que dele lançam mão, já que não têm a certeza que ele será respeitado pela equipe médica e seus familiares.

\section{CONCLUSÃO}

A promulgação da Constituição Federal de 1988 veio a consagrar o Estado Democrático de Direito, garantindo que toda pessoa possa viver com dignidade, respeitando sua autonomia de vontade e liberdade para praticar atos não proibidos por lei. 


\section{Personalidade Acadêmica Homenageada:}

\section{Carlos Aurélio Mota de Souza (Universidade Ibirapuera - UNIB)}

Da mesma forma que é garantido ao indivíduo viver com dignidade, também Ihe está garantido o direito de morrer de forma digna, respeitando sua última vontade em vida. Nesse diapasão, o testamento vital é o instrumento que possibilita a manifestação de vontade de um paciente enquanto em pleno gozo de suas faculdades mentais, dispondo sobre os tratamentos e procedimentos que deseja, ou não, ser submetido quando se encontrar incapaz de manifestar sua vontade.

Como visto, no âmbito médico, o testamento vital foi consolidado por meio da Resolução № 1995/2012, expedida pelo Conselho Federal de Medicina, que buscou regulamentar a conduta do médico quando se deparar com um caso em que o paciente se recusa a receber qualquer tipo de procedimento que prolongue seu processo de morte artificialmente, muito embora inexista no ordenamento jurídico brasileiro a figura do testamento vital, mas tão somente projetos de lei em trâmite no Congresso Nacional.

Diante da ausência de previsão legal, poder-se-ia pensar na vedação do uso do instituto no Brasil, contudo, esta não é a verdade. A doutrina e a jurisprudência estão fortemente caminhando no sentido de amparar o instituto, dando-Ihe validade por meio da interpretação sistemática dos princípios constitucionais, dentre eles o referencial princípio da dignidade da pessoa humana.

Por óbvio que não se afasta a necessidade da edição de lei específica para garantir maior eficácia, credibilidade e segurança para o paciente e para o médico, contudo, enquanto isso, muitos instrumentos estão sendo redigidos por pessoas que se um dia se encontrarem em estado terminal, acometidos por doença incurável, terão disciplinados em documento particular ou público todas as especificações do tipo de tratamento e procedimento que aceita se submeter, podendo recusar a utilização de métodos artificiais para mantê-lo vivo.

\section{REFERÊNCIAS}

ALMEIDA, J. L. T. de. Respeito à autonomia do paciente e consentimento livre e esclarecido: uma abordagem principialista da relação médico-paciente. Fundação Oswaldo Cruz, Escola Nacional de Saúde Pública; 1999. 
Personalidade Acadêmica Homenageada:

Carlos Aurélio Mota de Souza (Universidade Ibirapuera - UNIB)

COSTA, Guilherme. Testamento Vital. Disponível em https://guilh.jusbrasil.com.br/artigos/305242650/testamento-vital?ref=amp. Acessado em 29/08/2018.

CLOTET, J. O consentimento informado: uma questão do interesse de todos. Jornal MEDICINA do Conselho Federal, out/nov, 2000.

DADALTO, Luciana. Testamento vital. Rio de Janeiro: Editora Lumen Juris, 2013.

ESTIGARA, Adriana. Consentimento livre e esclarecido na pesquisa envolvendo seres humanos. Disponível em http://www.egov.ufsc.br/portal/conteudo/consentimento-livre-eesclarecido-napesquisa-envolvendo-seres-humanos. Acessado em 29/08/2018.

FREIRE JUNIOR, Aluer Baptista. AMIGO, Andréia Vieira. A legitimidade do testamento vital. Disponível em http://jus.com.br/artigos/26316/a-legitimidade-dotestamento-vital. Acessado em 29/08/2018.

GONÇALVES, Carlos Roberto. Direito Civil Brasileiro: Direito das Sucessões, São Paulo: Editora Saraiva, 2015.

GOMES. Luiz Flávio. Testamento Vital e a Ortotanásia. Disponível em https://professorlfg.jusbrasil.com.br/artigos/121929832/testamento-vital-e-aortotanasia. Acesso em 29/08/2018.

GOLDIM, J. R. Núcleo Interdisciplinar de Bioética do Hospital de Clínicas de Porto Alegre. Princípio do Respeito à pessoa ou da autonomia. Disponível em https://www.ufrgs.br/bioetica/autonomi.htm. Acesso em 30/08/2018.

GONÇALVES, Carlos Roberto. Direito Civil Brasileiro: Direito das Sucessões, São Paulo: Editora Saraiva, 2015.

GOMES. Luiz Flávio. Testamento Vital e a Ortotanásia. Disponível em https://professorlfg.jusbrasil.com.br/artigos/121929832/testamento-vital-e-aortotanasia. Acesso em 29/08/2018.

OLIVEIRA, Gabriela de. Testamento Vital em face do ordenamento jurídico brasileiro. Disponível em file://C:/Users/FABIANA\%20CARICATI/Desktop/MESTRADO/Testamento\%20vital.p df. Acesso em 28 de agosto de 2018.

MORITZ, Rachel Duarte. Conflitos bioéticos do morrer e do viver. Brasília: Conselho Federal de Medicina, 2011. Disponível em 
Personalidade Acadêmica Homenageada:

Carlos Aurélio Mota de Souza (Universidade Ibirapuera - UNIB)

https://portal.cfm.org.br/images/stories/biblioteca/conflitos.pdf. Acesso em 29 de agosto de 2018.

SANTOS, Maria Celeste Cordeiro Leite. O Equilíbrio de um pêndulo. Bioética e a Lei: implicações médico-legais. São Paulo: İcone Editora, 1998. 